\title{
Modified Ratio Estimators Using Known Median and Co-Efficent of Kurtosis
}

\author{
J.Subramani", G.Kumarapandiyan \\ Department of Statistics, Pondicherry University, R V Nagar, Kalapet, Puducherry ,605014, India \\ drjsubramani@yahoo.co.in, kumarstat88@gmail.com
}

\begin{abstract}
The present paper deals with two modified ratio estimators for estimation of population mean of the study variable using the linear combination of the known population values of the Median and the Co-efficient of Kurtosis of the auxiliary variable. The biases and the mean squared errors of the proposed estimators are derived and are compared with that of existing modified ratio estimators for certain natural populations. Further we have also derived the conditions for which the proposed estimators perform better than the existing modified ratio estimators. From the numerical study it is also observed that the proposed modified ratio estimators perform better than the existing modified ratio estimators.
\end{abstract}

Keywords Auxiliary Variable, Bias, Modified Ratio Estimators, Simple Random Sampling

\section{Introduction}

Consider a finite population $\mathrm{U}=\left\{\mathrm{U}_{1}, \mathrm{U}_{2}, \ldots, \mathrm{U}_{\mathrm{N}}\right\}$ of $\mathrm{N}$ distinct and identifiable units. Let $\mathrm{Y}$ is a study variable with value $Y_{i}$ measured on $U_{i}, i=1,2,3, \ldots, N$ giving a vector $Y=\left\{Y_{1}, Y_{2}, \ldots, Y_{N}\right\}$. The problem is to estimate the population mean $\bar{Y}=\frac{1}{N} \sum_{i=1}^{N} Y_{i}$ with some desirable properties on the basis of a random sample selected from the population $U$. The simplest estimator of population mean is the sample mean obtained by using simple random sampling without replacement, when there is no additional information on the auxiliary variable available. Sometimes in sample surveys, along with the study variable $\mathrm{Y}$, information on auxiliary variable $\mathrm{X}$, correlated with $\mathrm{Y}$ is also collected. This information on auxiliary variable $\mathrm{X}$, may be utilized to obtain a more efficient estimator of the population mean. Ratio method of estimation, using auxiliary information is an attempt made in this direction. Before discussing further about the modified ratio estimators and the proposed modified ratio estimators the notations to be used are described.

- $\mathrm{N}$ - Population size

- $\mathrm{n}$ - Sample size

- $\mathrm{f}=\mathrm{n} / \mathrm{N}$, Sampling fraction

- Y - Study variable

- $X$ - Auxiliary variable

- $\bar{X}, \bar{Y}-$ Population means

* Corresponding author:

drjsubramani@yahoo.co.in (J. Subramani)

Published online at http://journal.sapub.org/ajms

Copyright (C) 2012 Scientific \& Academic Publishing. All Rights Reserved
- $\overline{\mathrm{x}}, \overline{\mathrm{y}}-$ Sample means

- $\mathrm{S}_{\mathrm{X}}, \mathrm{S}_{\mathrm{y}}-$ Population standard deviations

- $\mathrm{C}_{\mathrm{X}}, \mathrm{C}_{\mathrm{v}}-$ Co-efficient of variations

- $\rho-$ Co-efficient of correlation

- $\beta_{1}=\frac{\mathrm{N} \sum_{\mathrm{i} 1}^{\mathrm{N}}\left(\mathrm{X}_{\mathrm{i}}-\overline{\mathrm{X}}\right)^{3}}{(\mathrm{~N}-1)(\mathrm{N}-2) \mathrm{S}^{3}}$, Co-efficient of skewness of the auxiliary variable

- $\beta_{2}=\frac{\mathrm{N}(\mathrm{N}+1) \sum_{i=1}^{\mathrm{N}}\left(\mathrm{X}_{\mathrm{i}}-\overline{\mathrm{X}}\right)^{4}}{(\mathrm{~N}-1)(\mathrm{N}-2)(\mathrm{N}-3) \mathrm{S}^{4}}-\frac{3(\mathrm{~N}-1)^{2}}{(\mathrm{~N}-2)(\mathrm{N}-3)}$, Co-efficient of kurtosis of the auxiliary variable

- $\mathrm{M}_{\mathrm{d}}-$ Median of the auxiliary variable

- $\mathrm{B}($.$) - Bias of the estimator$

- MSE(.) - Mean squared error of the estimator

- $\widehat{\widehat{Y}}_{\mathrm{i}}\left(\widehat{\bar{Y}}_{\mathrm{pi}}\right)$ - Existing (proposed) modified ratio estimator of $\bar{Y}$

The Ratio estimator for estimating the population mean $\bar{Y}$ of the study variable $\mathrm{Y}$ is defined as

$$
\widehat{\mathrm{Y}}_{\mathrm{R}}=\frac{\overline{\mathrm{y}}}{\overline{\mathrm{X}}} \overline{\mathrm{X}}=\widehat{\mathrm{R}} \overline{\mathrm{X}}
$$

where $\widehat{R}=\frac{\bar{y}}{\bar{x}}=\frac{y}{x}$ is the estimate of $R=\frac{\bar{Y}}{\bar{X}}=\frac{Y}{X}$

The Ratio estimator given in (1) is more precise than the simple random sample mean, when there exists a positive correlation between $X$ and $Y$. Sen [8] has presented the historical developments of the ratio method of estimation starting from the year 1662 . Hence the readers, who are interested in knowing more details on the chronological developments of the ratio methods of estimation, are referred to Sen [8] and the references cited therein. Further improvements are also achieved on the classical ratio estimator by introducing a large number of modified ratio estimators with the use of known parameters like, Co-efficient of Variation, Co-efficient of Kurtosis, Co-efficient of Skewness, Population Correlation Coefficient and Median. It is to be noted that "the existing modified ratio estimators" 
means the list of modified ratio estimators to be considered in this paper unless otherwise stated. It does not mean to the entire list of modified ratio estimators available in the literature. For a more detailed discussion on the ratio estimator and its modifications one may refer to Cochran[1], Kadilar and Cingi[2,3], Koyuncu and Kadilar[4], Murthy[5], Prasad[6], Rao[7], Singh[10], Singh and Tailor[11,12], Singh et.al[13], Sisodia and Dwivedi[14], Srivastava [15,16], Subramani and Kumarapandiyan[17,18], Upadhyaya and Singh[19], Walsh [20], Yan and Tian[21] and the references cited there in.

The lists of modified ratio estimators together with their biases, mean squared errors and constants available in the literature are classified into two classes namely Class 1, Class 2 and are given respectively in Table 1 and Table 2 respectively.

The modified ratio estimators given in Table 1 and Table 2 are biased but have minimum mean squared errors compared to the classical ratio estimator. The list of estimators given in Table 1 and Table 2 uses the known values of the parameters like $\bar{X}, C_{x}, \beta_{1}, \beta_{2}, \rho, M_{d}$ and their linear combinations. However, it seems, no attempt is made to use the linear combination of known values of the Median and Co-efficient of Kurtosis of the auxiliary variable to improve the ratio estimator. The points discussed above have motivated us to introduce two modified ratio estimators using the linear combination of the known values of Median and Co-efficient of Kurtosis of the auxiliary variable. It is observed that the proposed estimators perform better than the existing modified ratio estimators listed in Table 1 and Table 2.

\section{Proposed Modified Ratio Estimators}

In this section, we have suggested two modified ratio estimators using the linear combination of Median and Co-efficient of Kurtosis of the auxiliary variable. The proposed modified ratio estimators for estimating the population mean $\bar{Y}$ together with the first degree of approximation, the biases and mean squared errors and the constants are given below:

$$
\begin{gathered}
\widehat{\bar{Y}}_{\mathrm{p} 1}=\overline{\mathrm{y}}\left[\frac{\overline{\mathrm{X}} \beta_{2}+\mathrm{M}_{\mathrm{d}}}{\overline{\mathrm{x}} \beta_{2}+\mathrm{M}_{\mathrm{d}}}\right] \\
\mathrm{B}\left(\widehat{\overline{\mathrm{Y}}}_{\mathrm{p} 1}\right)=\frac{(1-\mathrm{f})}{\mathrm{n}} \overline{\mathrm{Y}}\left(\theta_{\mathrm{p} 1}^{2} \mathrm{C}_{\mathrm{x}}^{2}-\theta_{\mathrm{p} 1} \mathrm{C}_{\mathrm{x}} \mathrm{C}_{\mathrm{y}} \rho\right) \\
\operatorname{MSE}\left(\widehat{\overline{\mathrm{Y}}}_{\mathrm{p} 1}\right)=\frac{(1-\mathrm{f})}{\mathrm{n}} \overline{\mathrm{Y}}^{2}\left(\mathrm{C}_{\mathrm{y}}^{2}+\theta_{\mathrm{p} 1}^{2} \mathrm{C}_{\mathrm{x}}^{2}-2 \theta_{\mathrm{p} 1} \mathrm{C}_{\mathrm{x}} \mathrm{C}_{\mathrm{y}} \rho\right) \\
\text { where } \theta_{\mathrm{p} 1}=\frac{\overline{\mathrm{X}} \beta_{2}}{\overline{\mathrm{X}} \beta_{2}+\mathrm{M}_{\mathrm{d}}} \\
\widehat{\mathrm{Y}}_{\mathrm{p} 2}=\frac{\overline{\mathrm{y}}+\mathrm{b}(\overline{\mathrm{X}}-\overline{\mathrm{x}})}{\left(\overline{\mathrm{x}} \beta_{2}+\mathrm{M}_{\mathrm{d}}\right)}\left(\overline{\mathrm{X}} \beta_{2}+\mathrm{M}_{\mathrm{d}}\right) \\
\mathrm{B}\left(\widehat{\mathrm{Y}}_{\mathrm{p} 2}\right)=\frac{(1-\mathrm{f})}{\mathrm{n}} \frac{S_{\mathrm{x}}^{2}}{\overline{\mathrm{Y}}} \mathrm{R}_{\mathrm{p} 2}^{2} \\
\operatorname{MSE}\left(\widehat{\mathrm{Y}}_{\mathrm{p} 2}\right)=\frac{(1-\mathrm{f})}{\mathrm{n}}\left(\mathrm{R}_{\mathrm{p} 2}^{2} S_{\mathrm{x}}^{2}+\mathrm{S}_{\mathrm{y}}^{2}\left(1-\rho^{2}\right)\right) \\
\text { where } \mathrm{R}_{\mathrm{p} 2}=\frac{\overline{\mathrm{Y}} \beta_{2}}{\overline{\mathrm{x}} \beta_{2}+\mathrm{M}_{\mathrm{d}}}
\end{gathered}
$$

\section{Efficiency Comparison}

For want of space; for the sake of convenience to the readers and for the ease of comparisons, the modified ratio

\begin{tabular}{|c|c|c|c|}
\hline Estimator & Bias - B(.) & Mean squared error MSE(.) & Constant $\boldsymbol{\theta}_{\mathbf{i}}$ \\
\hline $\begin{array}{c}\widehat{\mathrm{Y}}_{1}=\overline{\mathrm{y}}\left[\frac{\overline{\mathrm{X}} \mathrm{C}_{\mathrm{x}}+\beta_{2}}{\overline{\mathrm{x}} \mathrm{C}_{\mathrm{x}}+\beta_{2}}\right] \\
\text { Upadhyaya and Singh[19] }\end{array}$ & $\frac{(1-f)}{n} \bar{Y}\left(\theta_{1}^{2} C_{x}^{2}-\theta_{1} C_{x} C_{y} \rho\right)$ & $\frac{(1-f)}{n} \bar{Y}^{2}\left(C_{y}^{2}+\theta_{1}^{2} C_{x}^{2}-2 \theta_{1} C_{x} C_{y} \rho\right)$ & $\theta_{1}=\frac{\overline{\mathrm{X}} \mathrm{C}_{\mathrm{x}}}{\overline{\mathrm{X}} \mathrm{C}_{\mathrm{x}}+\beta_{2}}$ \\
\hline $\begin{array}{c}\widehat{\mathrm{Y}}_{2}=\overline{\mathrm{y}}\left[\frac{\overline{\mathrm{X}} \beta_{2}+\mathrm{C}_{\mathrm{x}}}{\overline{\mathrm{x}} \beta_{2}+\mathrm{C}_{\mathrm{x}}}\right] \\
\text { Upadhyaya and Singh[19] }\end{array}$ & $\frac{(1-f)}{n} \bar{Y}\left(\theta_{2}^{2} C_{x}^{2}-\theta_{2} C_{x} C_{y} \rho\right)$ & $\frac{(1-f)}{n} \bar{Y}^{2}\left(C_{y}^{2}+\theta_{2}^{2} C_{x}^{2}-2 \theta_{2} C_{x} C_{y} \rho\right)$ & $\theta_{2}=\frac{\bar{x} \beta_{2}}{\bar{X} \beta_{2}+C_{x}}$ \\
\hline $\begin{array}{c}\widehat{\mathrm{Y}}_{3}=\overline{\mathrm{y}}\left[\frac{\overline{\mathrm{X}} \beta_{2}+\beta_{1}}{\overline{\mathrm{x}} \beta_{2}+\beta_{1}}\right] \\
\text { Yan and Tian[21] }\end{array}$ & $\frac{(1-f)}{n} \bar{Y}\left(\theta_{3}^{2} C_{x}^{2}-\theta_{3} C_{x} C_{y} \rho\right)$ & $\frac{(1-f)}{n} \bar{Y}^{2}\left(C_{y}^{2}+\theta_{3}^{2} C_{x}^{2}-2 \theta_{3} C_{x} C_{y} \rho\right)$ & $\theta_{3}=\frac{\bar{x} \beta_{2}}{\bar{x} \beta_{2}+\beta_{1}}$ \\
\hline $\begin{array}{l}\widehat{\mathrm{Y}}_{4}=\overline{\bar{y}}\left[\frac{\overline{\mathrm{X}} \beta_{1}+\beta_{2}}{\overline{\overline{\mathrm{X}}} \beta_{1}+\beta_{2}}\right] \\
\text { Yan and Tian[21] }\end{array}$ & $\frac{(1-f)}{n} \bar{Y}\left(\theta_{4}^{2} C_{x}^{2}-\theta_{4} C_{x} C_{y} \rho\right)$ & $\frac{(1-f)}{n} \bar{Y}^{2}\left(C_{y}^{2}+\theta_{4}^{2} C_{x}^{2}-2 \theta_{4} C_{x} C_{y} \rho\right)$ & $\theta_{4}=\frac{\bar{x} \beta_{1}}{\bar{X} \beta_{1}+\beta_{2}}$ \\
\hline
\end{tabular}
estimators given in Table 1, Table 2 are represented into two classes as given below. Further it is to be noted that the proposed estimator $\widehat{\mathrm{Y}}_{\mathrm{p} 1}$ is compared with that of the modified ratio estimators listed in Class 1 whereas the proposed estimator $\widehat{\mathrm{Y}}_{\mathrm{p} 2}$ is compared with that of the modified ratio estimators listed in Class 2.

Table 1. Existing modified ratio estimators (Class 1) with their biases, mean squared errors and their constants 
Table 2. Existing modified ratio estimators (Class 2) with their biases, mean squared errors and their constants

\begin{tabular}{|c|c|c|c|}
\hline Estimator & Bias-B(.) & Mean squared error MSE(.) & Constant $\mathbf{R}_{\mathbf{i}}$ \\
\hline $\begin{array}{c}\widehat{\widehat{Y}}_{5}=\frac{\bar{y}+b(\bar{x}-\bar{x})}{\left(\bar{x} \beta_{2}+C_{x}\right)}\left(\bar{X} \beta_{2}+C_{x}\right) \\
\text { Kadilar and Cingi[2] }\end{array}$ & $\frac{(1-f)}{n} \frac{S_{X}^{2}}{\bar{Y}} R_{5}^{2}$ & $\frac{(1-f)}{n}\left(R_{5}^{2} S_{x}^{2}+S_{y}^{2}\left(1-\rho^{2}\right)\right)$ & $R_{5}=\frac{\bar{Y} \beta_{2}}{\overline{\mathrm{X}} \beta_{2}+C_{x}}$ \\
\hline $\begin{array}{c}\widehat{\widehat{\mathrm{Y}}}_{6}=\frac{\overline{\mathrm{y}}+\mathrm{b}(\overline{\mathrm{X}}-\overline{\mathrm{x}})}{\left(\overline{\mathrm{x}} \mathrm{C}+\beta_{2}\right)}\left(\overline{\mathrm{X}} \mathrm{C}_{\mathrm{x}}+\beta_{2}\right) \\
\text { Kadilar and Cingi[2] }\end{array}$ & $\frac{(1-f)}{n} \frac{S_{X}^{2}}{\bar{Y}} R_{6}^{2}$ & $\frac{(1-f)}{n}\left(R_{6}^{2} S_{x}^{2}+S_{y}^{2}\left(1-\rho^{2}\right)\right)$ & $\mathrm{R}_{6}=\frac{\overline{\mathrm{Y}} \mathrm{C}_{\mathrm{x}}}{\overline{\mathrm{X}} \mathrm{C}_{\mathrm{x}}+\beta_{2}}$ \\
\hline $\begin{array}{c}\widehat{\widehat{Y}}_{7}=\frac{\bar{y}+b(\bar{x}-\bar{x})}{\left(\overline{\mathrm{x}} \beta_{1}+\beta_{2}\right)}\left(\bar{X} \beta_{1}+\beta_{2}\right) \\
\text { Yan and Tian[21] }\end{array}$ & $\frac{(1-f)}{n} \frac{S_{X}^{2}}{\bar{Y}} R_{7}^{2}$ & $\frac{(1-\mathrm{f})}{\mathrm{n}}\left(\mathrm{R}_{7}^{2} S_{x}^{2}+S_{y}^{2}\left(1-\rho^{2}\right)\right)$ & $\mathrm{R}_{7}=\frac{\overline{\mathrm{Y}} \beta_{1}}{\overline{\overline{\mathrm{X}} \beta_{1}+\beta_{2}}}$ \\
\hline $\begin{array}{c}\widehat{\mathrm{Y}}_{8}=\frac{\overline{\mathrm{y}}+\mathrm{b}(\overline{\mathrm{x}}-\overline{\mathrm{x}})}{\left(\overline{\mathrm{x}} \beta_{2}+\rho\right)}\left(\overline{\mathrm{X}} \beta_{2}+\rho\right) \\
\text { Kadilar and Cingi[3] }\end{array}$ & $\frac{(1-f)}{n} \frac{S_{X}^{2}}{\bar{Y}} R_{8}^{2}$ & $\frac{(1-f)}{n}\left(R_{8}^{2} S_{x}^{2}+S_{y}^{2}\left(1-\rho^{2}\right)\right)$ & $\mathrm{R}_{8}=\frac{\overline{\mathrm{Y}} \beta_{2}}{\overline{\overline{\mathrm{X}}} \beta_{2}+\rho}$ \\
\hline $\begin{array}{c}\widehat{\mathrm{Y}}_{9}=\frac{\overline{\mathrm{y}}+\mathrm{b}(\overline{\mathrm{x}}-\overline{\mathrm{x}})}{\left(\overline{\mathrm{x}} \rho+\beta_{2}\right)}\left(\overline{\mathrm{X}} \rho+\beta_{2}\right) \\
\text { Kadilar and Cingi }[3]\end{array}$ & $\frac{(1-f)}{n} \frac{S_{X}^{2}}{\bar{Y}} R_{9}^{2}$ & $\frac{(1-f)}{n}\left(R_{9}^{2} S_{x}^{2}+S_{y}^{2}\left(1-\rho^{2}\right)\right)$ & $\mathrm{R}_{9}=\frac{\overline{\mathrm{Y}} \rho}{\overline{\mathrm{X}_{\rho}+\beta_{2}}}$ \\
\hline
\end{tabular}

Class 1:The biases, the mean squared errors and the constants of the modified ratio estimators $\widehat{\bar{Y}}_{1}$ to $\widehat{\bar{Y}}_{4}$ listed in the Table 1 are represented in a single class (say, Class 1), which will be very much useful for comparing with that of proposed modified ratio estimators and are given below:

$$
\begin{gathered}
B\left(\widehat{\bar{Y}}_{i}\right)=\frac{(1-f)}{n} \bar{Y}\left(\theta_{i}^{2} C_{x}^{2}-\theta_{i} C_{x} C_{y} \rho\right) \\
\operatorname{MSE}\left(\widehat{\bar{Y}}_{i}\right)=\frac{(1-f)}{n} \bar{Y}^{2}\left(C_{y}^{2}+\theta_{i}^{2} C_{x}^{2}-2 \theta_{i} C_{x} C_{y} \rho\right) ; i=1,2,3,4
\end{gathered}
$$$$
\text { where } \theta_{1}=\frac{\bar{x} C_{x}}{\bar{x} C_{x}+\beta_{2}}, \theta_{2}=\frac{\bar{x} \beta_{2}}{\bar{x} \beta_{2}+C_{x}}, \theta_{3}=\frac{\bar{x} \beta_{2}}{\bar{x} \beta_{2}+\beta_{1}} \text { and } \theta_{4}=
$$

$$
\frac{\overline{\mathrm{X}} \beta_{1}}{\overline{\mathrm{x}} \beta_{1}+\beta_{2}}
$$

Class 2:The biases, the mean squared errors and the constants of the remaining 5 modified ratio estimators $\widehat{\widehat{Y}}_{5}$ to $\widehat{\widehat{Y}}_{9}$ listed in the Table 2 are represented in a single class (say, Class 2), which will be very much useful for comparing with that of proposed modified ratio estimators and are given below:

$$
\begin{gathered}
B\left(\widehat{\bar{Y}}_{i}\right)=\frac{(1-f)}{n} \frac{S_{x}^{2}}{\bar{Y}} R_{i}^{2} \\
\operatorname{MSE}\left(\widehat{Y}_{i}\right)=\frac{(1-f)}{n}\left(R_{i}^{2} S_{x}^{2}+S_{y}^{2}\left(1-\rho^{2}\right)\right) ; i=5,6,7,8,9 \\
\text { where } R_{5}=\frac{\bar{Y} \beta_{2}}{\bar{X} \beta_{2}+C_{x}}, R_{6}=\frac{\bar{Y} C_{x}}{\overline{\bar{X}} C_{x}+\beta_{2}}, R_{7}=\frac{\bar{Y} \beta_{1}}{\overline{\mathrm{X}} \beta_{1}+\beta_{2}}, R_{8}= \\
\frac{\overline{\mathrm{Y}} \beta_{2}}{\overline{\mathrm{B}} \beta_{2}+\rho} \text { and } R_{9}=\frac{\overline{\mathrm{Y} \rho}}{\overline{\mathrm{X}} \rho+\beta_{2}}
\end{gathered}
$$

As derived earlier in section 2 , the biases, the mean squared errors and the constants of two proposed modified ratio estimators are given below:

$$
\begin{gathered}
\mathrm{B}\left(\widehat{\overline{\mathrm{Y}}}_{\mathrm{p} 1}\right)=\frac{(1-\mathrm{f})}{\mathrm{n}} \overline{\mathrm{Y}}\left(\theta_{\mathrm{p} 1}^{2} \mathrm{C}_{\mathrm{x}}^{2}-\theta_{\mathrm{p} 1} \mathrm{C}_{\mathrm{x}} \mathrm{C}_{\mathrm{y}} \rho\right) \\
\operatorname{MSE}\left(\widehat{\mathrm{Y}}_{\mathrm{p} 1}\right)=\frac{(1-\mathrm{f})}{\mathrm{n}} \overline{\mathrm{Y}}^{2}\left(\mathrm{C}_{\mathrm{y}}^{2}+\theta_{\mathrm{p} 1}^{2} \mathrm{C}_{\mathrm{x}}^{2}-2 \theta_{\mathrm{p} 1} \mathrm{C}_{\mathrm{x}} \mathrm{C}_{\mathrm{y}} \rho\right) \\
\text { where } \theta_{\mathrm{p} 1}=\frac{\overline{\mathrm{X}} \beta_{2}}{\overline{\mathrm{X}} \beta_{2}+\mathrm{M}_{\mathrm{d}}} \\
\left.\operatorname{MSE}\left(\widehat{\overline{\mathrm{Y}}}_{\mathrm{p} 2}\right)=\frac{(1-\mathrm{f})}{\mathrm{n}}\left(\widehat{\mathrm{Y}}_{\mathrm{p} 2}^{2}\right)=\frac{(1-\mathrm{f})}{\mathrm{n}} \frac{\mathrm{S}_{\mathrm{x}}^{2}}{\overline{\mathrm{Y}}} \mathrm{R}_{\mathrm{p} 2}^{2}+\mathrm{S}_{\mathrm{y}}^{2}\left(1-\rho^{2}\right)\right) \text { where } \mathrm{R}_{\mathrm{p} 2}= \\
\frac{\overline{\mathrm{Y}} \beta_{2}}{\overline{\mathrm{X}} \beta_{2}+\mathrm{M}_{\mathrm{d}}}
\end{gathered}
$$

From the expressions given in (4) and (6) we have derived the conditions for which the proposed estimator $\widehat{\bar{Y}}_{p 1}$ is more efficient than the existing modified ratio estimators given in Class $1, \widehat{\mathrm{Y}}_{\mathrm{i}} ; \mathrm{i}=1,2,3,4$ and are given below:

$$
\operatorname{MSE}\left(\widehat{\bar{Y}}_{\mathrm{p} 1}\right)<\operatorname{MSE}\left(\widehat{\mathrm{Y}}_{\mathrm{i}}\right) \text { if } \rho<\frac{\left(\theta_{\mathrm{p} 1}+\theta_{\mathrm{i}}\right)}{2} \frac{\mathrm{C}_{\mathrm{x}}}{\mathrm{C}_{\mathrm{y}}} ; \mathrm{i}=1,2,3,4
$$

From the expressions given in (5) and (7) we have derived the conditions for which the proposed estimator $\widehat{\bar{Y}}_{\mathrm{p} 2}$ is more efficient than the existing modified ratio estimators given in Class $2, \widehat{\widehat{Y}}_{i} ; i=5,6,7,8$ and 9 and are given below:

$$
\operatorname{MSE}\left(\widehat{\mathrm{Y}}_{\mathrm{p} 2}\right)<\operatorname{MSE}\left(\widehat{\mathrm{Y}}_{\mathrm{i}}\right) \text { if } \mathrm{R}_{\mathrm{p} 2}<\mathrm{R}_{\mathrm{i}} ; \mathrm{i}=5,6,7,8 \text { and } 9
$$

\section{Numerical Study}

The performances of the proposed modified ratio estimators are assessed with that of existing modified ratio estimators listed in Table 1 and Table 2 for certain natural populations. In this connection, we have considered four natural populations for the assessment of the performances of the proposed modified ratio estimators with that of existing modified ratio estimators. The population 1 and 2 are taken from Singh and Chaudhary[9] given in page 177, population 3 is taken from Singh and Chaudhary[9] given in page 141 and population 4 is taken from Cochran[1] given in page 152. The population parameters and the constants computed from the above populations are given below:

The constants of the existing and proposed modified ratio estimators for the above populations are given in the Table 4 and Table 5:

The biases of the existing and proposed modified ratio estimators for the above populations are given in the Table 6 and Table 7:

The mean squared errors of the existing and proposed modified ratio estimators for the above populations are given in the Table 8 and Table 9:

From the values of Table 6 and Table 7, it is observed that 
the bias of the proposed modified ratio estimator $\widehat{\bar{Y}}_{\mathrm{p} 1}$ is less than the biases of the existing modified ratio estimators $\widehat{\mathrm{Y}}_{\mathrm{i}} ; \mathrm{i}=1,2,3,4$ given in Class 1 and the bias of the proposed modified ratio estimator $\widehat{\bar{Y}}_{\mathrm{p} 2}$ is less than the biases of the existing modified ratio estimators $\widehat{\bar{Y}}_{i} ; i=5,6,7,8$ and 9 given in Class 2. Similarly from the values of Table 8 and Table 9, it is observed that the mean squared error of the proposed modified ratio estimator $\widehat{\bar{Y}}_{\mathrm{p} 1}$ is less than the mean squared errors of the existing modified ratio estimators $\widehat{\mathrm{Y}}_{\mathrm{i}} ; \mathrm{i}=1,2,3,4$ given in Class 1 and the mean squared error of the proposed modified ratio estimator $\widehat{\bar{Y}}_{\mathrm{p} 2}$ is less than the mean squared errors of the existing modified ratio estimators $\widehat{\bar{Y}}_{\mathrm{i}} ; \mathrm{i}=5,6,7,8$ and 9 given in Class 2 .

Table 3. Parameters and Constants of the Populations

\begin{tabular}{|c|c|c|c|c|}
\hline Parameters & Population 1 & Population 2 & Population 3 & Population 4 \\
\hline $\mathrm{N}$ & 34 & 34 & 22 & 49 \\
\hline $\mathrm{n}$ & 20 & 20 & 5 & 20 \\
\hline$\overline{\mathrm{Y}}$ & 856.4117 & 856.4117 & 22.6209 & 116.1633 \\
\hline $\mathrm{X}$ & 208.8823 & 199.4412 & 1467.5455 & 98.6735 \\
\hline$\rho$ & 0.4491 & 0.4453 & 0.9022 & 0.6904 \\
\hline $\mathrm{S}_{\mathrm{v}}$ & 733.1407 & 733.1407 & 33.0469 & 98.8286 \\
\hline $\mathrm{C}_{\mathrm{y}}$ & 0.8561 & 0.8561 & 1.4609 & 0.8508 \\
\hline $\mathrm{S}_{\mathrm{x}}$ & 150.5059 & 150.2150 & 2562.1449 & 102.9709 \\
\hline $\mathrm{C}_{\mathrm{x}}$ & 0.7205 & 0.7532 & 1.7459 & 1.0436 \\
\hline$\beta_{2}$ & 0.0978 & 1.0445 & 13.3694 & 5.9878 \\
\hline$\beta_{1}$ & 0.9782 & 1.1823 & 3.3914 & 2.4224 \\
\hline $\mathrm{M}_{\mathrm{d}}$ & 150.0000 & 142.5000 & 534.5000 & 64.0000 \\
\hline
\end{tabular}

Table 4. The constants of the (Class 1) existing and proposed modified ratio estimators

\begin{tabular}{|c|c|c|c|c|}
\hline \multirow{2}{*}{ Estimator } & \multicolumn{4}{|c|}{ Constants $\boldsymbol{\theta}_{\mathbf{i}}$} \\
\cline { 2 - 5 } & Population 1 & Population 2 & Population 3 & Population 4 \\
\hline$\hat{\mathrm{Y}}_{1}$ Upadhyaya and Singh[18] & 0.9994 & 0.9931 & 0.9948 & 0.9450 \\
\hline$\widehat{\mathrm{Y}}_{2}$ Upadhyaya and Singh[18] & 0.9658 & 0.9964 & 0.9999 & 0.9982 \\
\hline$\widehat{\mathrm{Y}}_{3}$ Yan and Tian[21] & 0.9542 & 0.9944 & 0.9998 & 0.9959 \\
\hline$\widehat{\mathrm{Y}}_{4}$ Yan and Tian[21] & 0.9995 & 0.9956 & 0.9973 & 0.9756 \\
\hline$\widehat{\mathrm{Y}}_{\mathrm{p} 1 \text { (Proposed estimator)* }}$ (Pros $^{*}$ & $0.1195^{*}$ & $0.5938^{*}$ & $0.9735^{*}$ & $0.9023^{*}$ \\
\hline
\end{tabular}

Table 5. The constants of the (Class 2 ) existing and proposed modified ratio estimators

\begin{tabular}{|c|c|c|c|c|}
\hline \multirow{2}{*}{ Estimator } & \multicolumn{4}{|c|}{ Constants $\mathbf{R}_{\mathbf{i}}$} \\
\cline { 2 - 5 } & Population 1 & Population 2 & Population 3 & Population 4 \\
\hline$\widehat{\mathrm{Y}}_{5}$ Kadilar and Cingi[2] & 3.9598 & 4.2786 & 0.0154 & 1.1752 \\
\hline$\widehat{\widehat{\mathrm{Y}}}_{6}$ Kadilar and Cingi[2] & 4.0973 & 4.2644 & 0.0153 & 1.1126 \\
\hline$\widehat{\mathrm{Y}}_{7}$ Yan and Tian[21] & 4.0980 & 4.2751 & 0.0154 & 1.1485 \\
\hline$\widehat{\mathrm{Y}}_{8}$ Kadilar and Cingi[3] & 4.0115 & 4.2849 & 0.0154 & 1.1759 \\
\hline$\widehat{\widehat{\mathrm{Y}}}_{9}$ Kadilar and Cingi[3] & 4.0957 & 4.2441 & 0.0153 & 1.0821 \\
\hline$\widehat{\mathrm{Y}}_{\mathrm{p} 2}$ (Proposed estimator)* $^{*}$ & $0.4899^{*}$ & $2.5499^{*}$ & $0.0150^{*}$ & $1.0622^{*}$ \\
\hline
\end{tabular}

Table 6. The biases of the (Class 1) existing and proposed modified ratio estimators

\begin{tabular}{|c|c|c|c|c|}
\hline \multirow{2}{*}{ Estimator } & \multicolumn{4}{|c|}{ Bias B(.) } \\
\cline { 2 - 5 } & Population 1 & Population 2 & Population 3 & Population 4 \\
\hline$\widehat{\mathrm{Y}}_{1}$ Upadhyaya and Singh[19] & 4.2607 & 4.8369 & 2.5432 & 1.3519 \\
\hline$\widehat{\mathrm{Y}}_{2}$ Upadhyaya and Singh[19] & 3.8212 & 4.8860 & 2.6106 & 1.6268 \\
\hline$\widehat{\widehat{Y}}_{3}$ Yan and Tian[21] & 3.6732 & 4.8556 & 2.6095 & 1.6144 \\
\hline$\widehat{\mathrm{Y}}_{4}$ Yan and Tian[21] & 4.2629 & 4.8739 & 2.5763 & 1.5070 \\
\hline$\widehat{\mathrm{Y}}_{\mathrm{p} 1}$ (Proposed estimator)* & $0.4529^{*}$ & $0.5207^{*}$ & $2.2674 *$ & $1.1462^{*}$ \\
\hline
\end{tabular}

Table 7. The biases of the (Class 2) existing and proposed modified ratio estimators

\begin{tabular}{|c|c|c|c|c|}
\hline \multirow{2}{*}{ Estimator } & \multicolumn{4}{|c|}{ Bias B(.) } \\
\cline { 2 - 5 } & Population 1 & Population 2 & Population 3 & Population 4 \\
\hline$\widehat{\mathrm{Y}}_{5}$ Kadilar and Cingi[2] & 8.5387 & 9.9303 & 10.6540 & 3.7302 \\
\hline$\widehat{\mathrm{Y}}_{6}$ Kadilar and Cingi[2] & 9.1421 & 9.8646 & 10.5456 & 3.3433 \\
\hline$\widehat{\mathrm{Y}}_{7}$ Yan and Tian[21] & 9.1452 & 9.9143 & 10.5989 & 3.5627 \\
\hline$\widehat{\widehat{Y}}_{8}$ Kadilar and Cingi[3] & 8.7629 & 9.9597 & 10.6549 & 3.7347 \\
\hline$\widehat{\mathrm{Y}}_{9}$ Kadilar and Cingi[3] & 9.1349 & 9.7711 & 10.4439 & 3.1630 \\
\hline$\widehat{\mathrm{Y}}_{\mathrm{p} 2 \text { (Proposed estimator)* }}$ (P) $^{*}$ & $0.1307^{*}$ & $3.5269^{*}$ & $10.0982^{*}$ & $3.0475^{*}$ \\
\hline
\end{tabular}


Table 8. The mean squared errors of the (Class 1) existing and proposed modified ratio estimators

\begin{tabular}{|c|c|c|c|c|}
\hline \multirow{2}{*}{ Estimator } & \multicolumn{4}{|c|}{ Mean Squared Error MSE(.) } \\
\cline { 2 - 5 } & Population 1 & Population 2 & Population 3 & Population 4 \\
\hline$\widehat{\mathrm{Y}}_{1}$ Upadhyaya and Singh[18] & 10534.5417 & 10902.7384 & 45.2894 & 214.7486 \\
\hline$\widehat{\mathrm{Y}}_{2}$ Upadhyaya and Singh[18] & 10298.4432 & 10930.3879 & 45.8857 & 233.6573 \\
\hline$\widehat{\mathrm{Y}}_{3}$ Yan and Tian[21] & 10220.4736 & 10913.2804 & 45.8758 & 232.7813 \\
\hline$\widehat{\mathrm{Y}}_{4}$ Yan and Tian[21] & 10535.7860 & 10923.6103 & 45.5814 & 225.2956 \\
\hline$\widehat{\mathrm{Y}}_{\mathrm{p} 1}$ (Proposed estimator)* & $10178.2990^{*}$ & $8937.4062^{*}$ & $42.9321^{*}$ & $201.3263^{*}$ \\
\hline
\end{tabular}

Table 9. The mean squared errors of the (Class 2) existing and proposed modified ratio estimators

\begin{tabular}{|c|c|c|c|c|}
\hline \multirow{2}{*}{ Estimator } & \multicolumn{4}{|c|}{ Mean Squared Error MSE(.) } \\
\cline { 2 - 5 } & Population 4 & Population 2 & Population 3 & Population 4 \\
\hline$\widehat{\mathrm{Y}}_{5}$ Kadilar and Cingi[2] & 16146.6142 & 17376.0389 & 272.4185 & 584.5606 \\
\hline$\widehat{\mathrm{Y}}_{6}$ Kadilar and Cingi[2] & 16663.3064 & 17319.7468 & 269.9654 & 539.6120 \\
\hline$\widehat{\mathrm{Y}}_{7}$ Yan and Tian[21] & 16665.9758 & 17362.2582 & 271.1716 & 565.0981 \\
\hline$\widehat{\mathrm{Y}}_{8}$ Kadilar and Cingi[3] & 16338.6465 & 17401.1397 & 272.4393 & 585.0781 \\
\hline$\widehat{\widehat{\mathrm{Y}}}_{9}$ Kadilar and Cingi[3] & 16657.1867 & 17239.6579 & 267.6660 & 518.6688 \\
\hline$\widehat{\mathrm{Y}}_{\mathrm{p} 2}$ (Proposed estimator)* $^{2}$ & $8945.8872^{*}$ & $11892.0742 *$ & $259.8459^{*}$ & $505.2469^{*}$ \\
\hline
\end{tabular}

\section{Conclusions}

In this paper we have proposed two modified ratio estimators using linear combination of Median and Co-efficient of Kurtosis of the auxiliary variable. The biases and mean squared errors of the proposed estimators are obtained and compared with that of existing modified ratio estimators. Further we have derived the conditions for which the proposed estimators are more efficient than the existing modified ratio estimators. We have also assessed the performances of the proposed estimators for some known populations. It is observed that the biases and mean squared errors of the proposed estimators are less than the biases and mean squared errors of the existing modified ratio estimators for certain known populations. Hence we strongly recommend that the proposed modified estimators may be preferred over the existing modified ratio estimators for the use of practical applications.

\section{ACKNOWLEDGEMENTS}

The authors are thankful to the referees whose constructive comments led to improvement in the paper. The second author wishes to record his gratitude and thanks to the Vice Chancellor, Pondicherry University and other University authorities for having given the financial assistance to carry out this research work through the University Fellowship.

\section{REFERENCES}

[1] Cochran, W. G. (1977). Sampling Techniques, Third Edition, Wiley Eastern Limited

[2] Kadilar, C. and Cingi, H. (2004). Ratio estimators in simple random sampling, Applied Mathematics and Computation $151,893-902$

[3] Kadilar, C. and Cingi, H. (2006). An Improvement in Esti- mating the Population mean by using the Correlation Co-efficient, Hacettepe Journal of Mathematics and Statistics Volume 35 (1), 103-109

[4] Koyuncu, N. and Kadilar, C. (2009). Efficient Estimators for the Population mean, Hacettepe Journal of Mathematics and Statistics, Volume 38(2), 217-225

[5] Murthy, M.N. (1967). Sampling theory and methods, Statistical Publishing Society, Calcutta, India

[6] Prasad, B. (1989). Some improved ratio type estimators of population mean and ratio in finite population sample surveys, Communications in Statistics: Theory and Methods 18, 379-392

[7] Rao, T.J. (1991). On certain methods of improving ratio and regression estimators, Communications in Statistics: Theory and Methods 20 (10), 3325-3340

[8] Sen, A.R. (1993): Some early developments in ratio estimation, Biometric Journal 35(1), 3-13

[9] Singh, D. and Chaudhary, F.S. (1986). Theory and Analysis of Sample Survey Designs, New Age International Publisher

[10] Singh, G.N. (2003). On the improvement of product method of estimation in sample surveys, Journal of the Indian Society of Agricultural Statistics 56 (3), 267-265

[11] Singh, H.P. and Tailor, R. (2003). Use of known correlation co-efficient in estimating the finite population means, Statistics in Transition 6 (4), 555-560

[12] Singh, H.P. and Tailor, R. (2005). Estimation of finite population mean with known co-efficient of variation of an auxiliary, STATISTICA, anno LXV, n.3, pp 301-313

[13] Singh, H.P., Tailor, R., Tailor, R. and Kakran, M.S. (2004). An Improved Estimator of population mean using Power transformation, Journal of the Indian Society of Agricultural Statistics 58(2), 223-230

[14] Sisodia, B.V.S. and Dwivedi, V.K. (1981). A modified ratio estimator using co-efficient of variation of auxiliary variable, Journal of the Indian Society of Agricultural Statistics 33(1), $13-18$

[15] Srivastava, S.K. (1967). An estimator using auxiliary infor- 
mation in sample surveys, Bulletin/Calcutta Statistical Association, vol. 16, pp.121-132

[16] Srivastava, S.K. (1980). A Class of estimators using auxiliary information in sample surveys, The Canadian Journal of Statistics, vol. 8, no.2, pp.253-254

[17] Subramani, J. and Kumarapandiyan, G. (2012). A Class of almost unbiased modified ratio estimators for population mean with known population parameters, Elixir Statistics 44, $7411-7415$

[18] Subramani, J. and Kumarapandiyan, G. (2012). Modified Ratio Estimator for Population Mean Using Median of the Auxiliary Variable, Proceedings of National Conference on Recent developments in the Applications of Reliability
Theory and Survival Analysis held on 2nd and 3rd February 2012 at the Department of Statistics, Pondicherry University

[19] Upadhyaya, L.N. and Singh, H.P. (1999). Use of transformed auxiliary variable in estimating the finite population mean, Biometrical Journal 41 (5), 627-636

[20] Walsh, J.E. (1970). Generalization of ratio estimator for population total, Sankhya, A, 32, 99-106

[21] Yan, Z. and Tian, B. (2010). Ratio Method to the Mean Estimation Using Co-efficient of Skewness of Auxiliary Variable, ICICA 2010, Part II, CCIS 106, pp. 103-110 